\title{
Polymorphism of apoptosis regulatory and growth factor genes in patients with chronic lymphocytic leukemia
}

\author{
Bulat A. Bakirov, D.O. Karimov, T.V. Viktorova
}

Bashkir State Medical University, Ufa, Russia

Accepted 23 May 2012

Original Text in Russian (C Bakirov BA, Karimov DO, Viktorova TV, 2011, published in Saratov Journal of Medical Scientific Research 2011; 7(4): 827-831.

\begin{abstract}
The objective of the research is to study the role of polymorphic gene variants of Tumor Necrosis Factor- $\alpha$ (TNFA), Bcl-2associated X protein (BAX), p53 Binding Protein (MDM2), vascular endothelial growth factor (VEGF) and basic fibroblast growth factor (bFGF) in the development of chronic lymphocytic leukemia (CLL).

Methods: The comparative analysis of allele and genotype frequency distribution in CLL patients ( $N=133$ ) and healthy individuals ( $N=196)$ from Bashkortostan Republic has been carried out.

Results: Analysis of distribution of genotype and allele frequencies of the genes under study has shown that patients with CLL were likely to demonstrate an increased frequency of GG-genotype and G-allele of polymorphic locus-308G>A of TNFA gene, GG-genotype and G-allele of the polymorphic locus-248G>A of BAX gene, G-allele of the polymorphic locus 309T> G of MDM2 gene and allele $C$ of polymorphic locus $773 \mathrm{C}>\mathrm{T}$ of bFGF gene.
\end{abstract}

Keywords: oncogenic genes, genetic polymorphism, chronic lymphocytic leukemia.

Cite as Bakirov BA, Karimov DO, Viktorova TV. Polymorphism of apoptosis regulatory and growth factor genes in patients with chronic lymphocytic leukemia. Russian Open Medical Journal 2012; 1: 0101.

Correspondence to Bulat A. Bakirov. Address: 132, Dostoevsky str., Ufa, 450000, Russia. Phone: +7 (347) 2289572, +7-917-776-9988.

E-mail: bakirovb@gmail.com

\section{Introduction}

Chronic lymphocytic leukemia (CLL) is an oncological disease of the lymphatic tissue which is characterized by accumulation of tumor cells in the peripheral blood, bone marrow and lymph nodes. CLL has a B-cell origin and is the most common type of all leukemias in adults [1].

Characteristic clinical symptoms of CLL include anemia, thrombocytopenia, enlargement of lymph nodes and hepatosplenomegaly. It has been established that at the time of diagnosis such symptoms appear to be absent in approximately $40 \%$ of patients. In most cases CLL is diagnosed in the later stages after the development of complications. Thus, the important task of oncohematology is to determine the prognostic criteria and to assess the risk for the development of the disease at the earliest stages possible [1, 2].

Like any other oncological process, CLL is most commonly caused by the disorder of apoptosis (tumor necrosis factor- $\alpha$ (TNF $\alpha$ ), main $\mathrm{p} 53$ protein regulator (MDM2), proapoptotic protein $\mathrm{BAX}$ ) and by interferences with cell proliferation control (vascular endothelial growth factor (VEGF), basic fibroblast growth factor (bFGF)). Mechanisms of apoptosis involve cytokines and tumor necrosis factor- $\alpha$ in particular (TNF $\alpha$; OMIM 191160). The effect of TNF $\alpha$ on tumor cells can be contributed to the disruption of mitochondrial function because its contact with specific receptors stimulates the development of oxidative stress, causes damage to cell membranes and DNA and finally induces their death. Gene
TNF $\alpha$, which encodes the corresponding cytokine, is located on the short arm of the $6^{\text {th }}$ chromosome at locus 6p21.1-6p21.3 [3].

Protein $\mathrm{p} 53$ is a transcription factor which regulates cell cycle and suppresses malignant transformation of cells (p53, OMIM 191170). Under normal conditions, p53 protein and the main regulator of the $\mathrm{p} 53$ tumor suppressor (MDM2) (OMIM 164785) are equally expressed. $\mathrm{N}$-terminal domain of MDM2 protein binds to the $\mathrm{N}$-terminal trans-activation domain of $\mathrm{p} 53$ protein, which results in the reduced activity of the latter. It has been shown that overexpression of MDM2 protein is an important factor in the progression of tumors [4]. MDM2 gene is localized on the long arm of the $12^{\text {th }}$ chromosome at locus $12 q 14.3-12 q 15$ [5].

Proteins of BC1-2 family, which perform their specific functions at the level of mitochondria, also play an important role in regulation of apoptotic processes. Members of this large family include proteins that prevent apoptosis and regulate proapoptotic proteins. BAX production is encoded by the gene $\mathrm{Bcl}-2$ associated $X$ protein (BAX, OMIM 600040). Its structure contains a region, which can bind to $p 53$ protein and cause, therefore, the activation of the gene. The BAX gene encodes a proapoptotic protein, which promotes the release of cytochrome $C$ from mitochondria. In combination with cytosolic protein APAF1 cytochrome $C$ participates in the activation of caspase 9, which triggers the apoptotic cascade. Consequently, reduced expression of BAX gene may impair the apoptotic processes and lead to tumor development. BAX gene in humans is located on the long arm of the $19^{\text {th }}$ chromosome at locus 19q13.3-q13.4 [6]. 
Table 1. Characteristics of the loci studied and conditions of their analysis

\begin{tabular}{|c|c|c|c|}
\hline Polymorphic variant & Primer sequences & Restriction endonuclease & Literary source \\
\hline \multirow[t]{2}{*}{-308G>A TNFA gene } & 5'-AGG CAA TAG GTT TTG AGG GCC AT-3' & Bsp19l & [7] \\
\hline & 5'-TCC TCC CTG CTC CGA TTC CG-3' & & \\
\hline \multirow[t]{2}{*}{$-248 \mathrm{G}>\mathrm{A}$ BAX gene } & 5'-CATTAGAGCTGCGATTGGACC G-3' & Mspl & [5] \\
\hline & 5'-GCTCC TCGGGAGGTTTGGT-3' & & \\
\hline \multirow[t]{2}{*}{ 309T>G MDM2 gene } & 5'-CGCGGGAGTTCAGGGTAAAG-3' & Msp A1I & [8] \\
\hline & 5'-CTGAGTCAACC TGCC ACTG-3' & & \\
\hline \multirow[t]{2}{*}{ 936C>T VEGF gene } & 5'-AGGAAGAGGAGACTCTGCGCAGAGC-3' & Hin1II & [10] \\
\hline & 5'-TAAATGTATGTATGTGGGTGGGTGTGTCTACAGG-3' & & \\
\hline \multirow[t]{2}{*}{$773 \mathrm{C}>\mathrm{T}$ bFGF gene } & 5'-CAGGATTTGTGTGCTGTGG-3' & BsuRI & [10] \\
\hline & 5'-GGTTCGAGAAGTTTTTTGAAGA-3' & & \\
\hline
\end{tabular}

$\mathrm{CLL}$ is also characterized by the impairment of hematopoietic processes which are regulated by a number of factors. The most important among them are vascular endothelial growth factor VEGF (OMIM 192240) and basic fibroblast growth factor bFGF (OMIM 134920). VEGF is a glycosylated mitogenic protein, which has a specific influence on endothelial cells and can cause various effects, including stimulation of angiogenesis, promotion of endothelial cell growth and proliferation, inhibition of their apoptosis [7]. In addition, VEGF regulates the processes of hematopoiesis, controlling the survival of hematopoietic stem cells. Various defects related to the suppression of VEGF function, lead to a decreased resistance of hematopoietic cells and the impairment of the process of colony formation. VEGF gene is located on the short arm of the $6^{\text {th }}$ chromosome at locus $6 \mathrm{p} 12$

BFGF is a protein of a broad spectrum of action, characterized by mitogenic, angiogenic and neurotrophic effect. It stimulates the proliferation of endothelial cells by activating Raf-1 serine/threonine-protein kinase and mediates the processes of formation of endothelial cells into capillary-like structures. BFGF protein is responsible for the rapid increase of proportion of blast cells (hemangioblasts), which are common precursors of hematopoietic and endothelial cells. BFGF gene is located on the short arm of the $4^{\text {th }}$ chromosome (4q25-q27).

The purpose of this study was to make a comparative analysis of polymorphic loci of TNFA gene (-308G $>A), B A X$ gene $(-248 G>A)$, MDM2 gene (309T>G), VEGF gene $(936 \mathrm{C}>\mathrm{T}$ ) and $\mathrm{bFGF}$ gene $(773 \mathrm{C}>\mathrm{T})$ in patients with CLL and healthy individuals from Bashkortostan Republic. The study also aimed to search for possible associations of polymorphic variants of these genes related to the development of CLL.

\section{Methods}

Molecular and genetic analysis of DNA samples was performed in 329 persons, all residents of the Bashkortostan Republic. The group of patients with CLL included 133 patients hospitalized to the hematology unit of the Republican Clinical Hospital of the Ufa city (2008-2010). All patients were selected at random. The average age was $49.6 \pm 1.4$ and male to female ratio made $75(56.4 \%)$ vs. $58(43.6 \%)$ respectively. According to ethnicity the patients with CLL appeared to include 62 Russians (46.6\%), 54 Tatars (40.6\%) and 17 Bashkirs (12.8\%). Clinical examination of the patients was carried out by hospital doctors and combined essential and optional methods of examination.

DNA samples from 196 apparently healthy individuals selected on the basis of age $(47.3 \pm 1.6)$, gender (107 men - 54.6\%, 89 women - 45.4\%) and ethnicity (97 Russians (49.5\%), 79 Tatars (40.3\%), 20 Bashkirs (10.2\%)) were used as controls.

DNA samples were isolated from lymphocytes of the peripheral venous blood by the method of phenol-chloroform extraction [8].

The polymorphic loci were studied by the method of polymerase chain reaction (PCR) of DNA synthesis. Genotyping was performed with the use of locus-specific oligonucleotide primers and restriction endonucleases taken from literary sources (Table 1).

Mathematical processing of the results was performed on IBM-Pentium IV with the use statistical programs BIOSTAT (Primer of Biostatistics, $4^{\text {th }}$ edition, SA Glantz, McGraw - Hill), Statistica, Microsoft Excel. $\chi^{2}$ criterion was calculated with application of Yates correction. Differences between frequencies of the compared genotypes or alleles of the gene under study were considered statistically significant if they were greater than $95 \%$ $(p<0.05)$ confidence level. The relative risk of the disease by characteristic sign was calculated as the odds ratio and its confidence interval.

\section{Results}

Genotype frequencies of polymorphic loci of TNA $\alpha$, BAX, MDM2, VEGF and bFGF genes in groups of patients and healthy individuals are shown in Table 2 . In all groups the distribution of genotype frequencies corresponded to the expected assumptions of Hardy - Weinberg equilibrium.

Comparison of the total sample of patients with CLL and control group revealed significant differences in genotype frequencies of polymorphic locus -308G>A of TNF $\alpha$ gene (Table 2).

In the group of patients with CLL the GG-genotype was significantly more common than that compared with the control group ( 82 and $65 \%$ respectively, $\chi^{2}=10.67, p=0.002$ ). The frequency of G-allele of polymorphic locus-308G $>A$ of TNF $\alpha$ gene in patients with CLL was higher than the corresponding result in the control group (91 and $81 \%$ respectively, $\chi^{2}=10.41, p=0.002$ ). The comparative analysis of the frequencies of polymorphic variants of locus-248G> A of BAX gene revealed significant differences in GG-genotype, which accounted for $74.30 \%$ in CLL patients and $46,30 \%$ in the control group $\left(\chi^{2}=16.25, p=0.001\right)$ (see Table 2).

Analysis of the polymorphic locus 309T>G of MDM2 gene revealed that the frequency of G-allele in patients with CLL was $46 \%$ compared to $37 \%$ in healthy individuals $\left(x^{2}=4.14, p=0.042\right.$; $\mathrm{OR}=1.47 ; 95 \% \mathrm{Cl}: 1.03-2.11)$. 
Genetics

\begin{tabular}{|c|c|c|c|c|c|c|c|}
\hline Polymorphic variant & $\begin{array}{l}\text { Genotypes, } \\
\text { alleles }\end{array}$ & $\begin{array}{l}\text { Patients } \\
(n=133)\end{array}$ & $\begin{array}{l}\text { Controls } \\
(n=196)\end{array}$ & $\chi^{2}$ & p-level & OR & $95 \% \mathrm{Cl}$ \\
\hline \multirow[t]{5}{*}{$-308 \mathrm{G}>\mathrm{A}$ TNFA gene } & GG & $81.95 \%$ & $64.80 \%$ & 10.67 & 0.002 & 2.46 & $1.45-4.19$ \\
\hline & GA & $17.30 \%$ & $32.70 \%$ & 8.84 & 0.004 & 0.43 & $0.25-0.74$ \\
\hline & AA & $0.80 \%$ & $2.60 \%$ & 0.6 & 0.438 & 0.29 & $0.03-2.51$ \\
\hline & G & $90.60 \%$ & $81.12 \%$ & 10.41 & 0.002 & 2.24 & $1.38-3.63$ \\
\hline & A & $9.40 \%$ & $18.90 \%$ & 10.41 & 0.002 & 0.44 & $0.27-0.72$ \\
\hline \multirow[t]{5}{*}{$-248 \mathrm{G}>\mathrm{A}$ BAX gene } & GG & $74.30 \%$ & $46.30 \%$ & 16.25 & 0.001 & 3.35 & $1.87-5.97$ \\
\hline & GA & $21.90 \%$ & $38.00 \%$ & 5.79 & 0.017 & 0.45 & $0.25-0.84$ \\
\hline & AA & $3.80 \%$ & $15.70 \%$ & 7.24 & 0.008 & 0.21 & $0.06-0.65$ \\
\hline & G & $85.20 \%$ & $65.30 \%$ & 21.64 & 0.001 & 3.07 & $1.91-4.93$ \\
\hline & A & $14.80 \%$ & $34.70 \%$ & 21.64 & 0.001 & 0.32 & $0.20-0.52$ \\
\hline \multirow[t]{5}{*}{ 309T>G MDM2 gene } & TT & $27.12 \%$ & $38.12 \%$ & 3.02 & 0.082 & 0.6 & $0.35-1.02$ \\
\hline & TG & $53.43 \%$ & $50.01 \%$ & 0.17 & 0.683 & 1.14 & $0.69-1.88$ \\
\hline & GG & $19.45 \%$ & $11.87 \%$ & 2.21 & 0.137 & 1.8 & $0.89-3.64$ \\
\hline & $\mathrm{T}$ & $53.80 \%$ & $63.10 \%$ & 4.14 & 0.042 & 0.67 & $0.47-0.97$ \\
\hline & G & . & $36.86 \%$ & .4 .14 & 0.042 & 1.47 & 1.03-2.10 \\
\hline \multirow[t]{5}{*}{$936 \mathrm{C}>\mathrm{T}$ VEGF gene } & CC & $96.12 \%$ & $99.17 \%$ & 1.32 & 0.256 & 0.21 & $0.02-1.82$ \\
\hline & CT & $3.10 \%$ & $0.83 \%$ & 0.68 & 0.413 & 3.81 & $0.42-34.57$ \\
\hline & TT & $0.78 \%$ & $0.00 \%$ & 0.01 & 0.978 & 0.01 & $0.99-19.08$ \\
\hline & C & $97.67 \%$ & $99.58 \%$ & 2.04 & 0.152 & 0.18 & $0.02-1.48$ \\
\hline & $\mathrm{T}$ & $2.33 \%$ & $0.42 \%$ & 2.04 & 0.152 & 5.69 & $0.68-47.62$ \\
\hline \multirow[t]{5}{*}{$773 \mathrm{C}>\mathrm{T}$ bFGF gene } & TT & $40.65 \%$ & $56.44 \%$ & 4.92 & 0.027 & 0.52 & $0.31-0.90$ \\
\hline & CT & $48.78 \%$ & $36.63 \%$ & 2.86 & 0.091 & 1.64 & $0.96-2.82$ \\
\hline & CC & $10.57 \%$ & $6.93 \%$ & 0.51 & 0.475 & 1.58 & $0.61-4.14$ \\
\hline & $\mathrm{T}$ & $65.00 \%$ & $74.75 \%$ & 4.48 & 0.035 & 0.62 & $0.41-0.94$ \\
\hline & C & $35.00 \%$ & $25.25 \%$ & 4.48 & 0.032 & 1.57 & $1.05-2.30$ \\
\hline
\end{tabular}

Cells with indicative significance level $(p<0.05)$ are bold typed.

Comparison of genotype and allele frequencies of polymorphic locus $936 \mathrm{C}>\mathrm{T}$ of VEGF gene in patients with CLL and in the control group did not reveal any significant differences.

TT genotype frequency of polymorphic locus $773 \mathrm{C}>\mathrm{T}$ of bFGF gene was higher in the control group than that in the group of patients ( 40.65 vs. $\left.56.44 \%, \chi^{2}=4.92 ; p=0.027\right)$. In contrast, the allele $C$ was more frequent in the group of patients (35.00 vs. $25.25 \%, \chi^{2}=4.48, p=0.03$ ).

\section{Discussion}

The study of mechanisms of tumor formation is a complicated multistep process in which mutations of genes play a significant role. Although a change in a single oncogene can cause a predisposition to cancer, the sequence of mutations of other oncogenes, such as tumor suppressor genes or genes controlling programmed cell death are considered necessary in the process of tumor development. Each of the genes of these three categories fulfills its role in a number of ways. The questions of how they interact in this multistage process of cancer cell development as well as what their role in the normal life processes are have not been fully clarified yet.

Cytokine TNFa plays an important role in protecting the body against tumor development through the induction of apoptosis in transformed cells. According to the literature, a guanine to adenine transition at position -308 of the promoter region of TNFa gene leads to an increased promoter activity and, therefore, to the enhanced gene expression [3]. Accordingly, the presence of GG- genotype can contribute to the reduced activity of this gene and initiate the processes of tumor development, which coincided with the data obtained during the study, particularly in relation to CLL.

MDM2 protein is an oncogenic factor since it directly affects the activation of the main regulator of the p53 tumor suppressor. According to the literature data, the G- allele of the polymorphic locus 309T $>\mathrm{G}$ of MDM2 gene is associated with increased expression of this gene. These information has been confirmed by our studies, where the $\mathrm{G}$-allele was associated with an increased risk of CLL (OR $=1.47 ; 95 \% \mathrm{Cl}: 1.03-2.11)$ [4].

The process of binding of $\mathrm{BCL}-2$ protein to the $\mathrm{BAX}$ gene results in formation of BCL-2-BAX complex and is accompanied by inhibition of apoptosis. It means that the impairment of the expression of this gene may contribute to oncogenic transformation and the development of CLL. As a result of the experiments an association of GG-genotype (OR $=3.35 ; 95 \% \mathrm{Cl}$ : 1.87-5.97) and G-allele (OR $=3.07 ; 95 \% \mathrm{Cl}$ : 1.91-4.93) of polymorphic locus $-248 \mathrm{G}>\mathrm{A}$ of $\mathrm{BAX}$ gene was found to represent risk for CLL development 6].

We also know that stem cells function in close contact with hematopoietic microenvironment, where spindle-shaped osteoblasts become an important component since they take part in formation of functional niche for quiescent stem cells [9]. Proliferating stem cells are located in the sinuses of the bone marrow and are related to endothelial cells which express different growth factors.

VEGF and bFGF are considered to be among the most important factors in the regulation of growth and differentiation of 
endothelial cells. Impaired interaction of stem cells with their microenvironment may lead to pathological changes in proliferation and differentiation of stem cells resulting finally in the development of CLL [10].

\section{Conclusion}

Thus, as a result of the study the following risk markers for CLL have been identified: GG-genotype of the polymorphic locus$308 \mathrm{G}>\mathrm{A}$ of TNFA gene $(\mathrm{OR}=1.74)$, GG- genotype and G-allele of the polymorphic locus-248G $>A$ of $B A X$ gene $(O R=1.07 ; O R=1.80$, respectively), $G$-allele of the polymorphic locus 309T $>G$ of MDM2 gene $(O R=1.07)$, allele $C$ of the polymorphic locus $773 \mathrm{C}>\mathrm{T}$ of $\mathrm{bFGF}$ gene $(O R=1.57)$.

\section{Reference}

1. Di Bernardo MC, Crowther-Swanepoel D, Broderick P, Webb E, Sellick $G$, Wild $R$, et al. A genome-wide association study identifies six susceptibility loci for chronic lymphocytic leukemia. Nat Genet 2008; 40(10): 1204-1210 (PMID: 18758461) (doi: 10.1038/ng.219).

2. Linet MS, Schubauer-Berigan MK, Weisenburger DD, Richardson DB, Landgren O, Blair A, et al. C hronic lymphocytic leukaemia: an overview of aetiology in light of recent developments in classification and pathogenesis. Br J Haematol 2007; 139(5): 86-94 (PMID: 18021081) (doi: 10.1111/j.1365-2141.2007.06847.x).

3. Kroeger KM, Carville KS, Abraham LJ. The -308 tumor necrosis factoralpha promoter polymorphism effects transcription. Mol Immunol 1997; 34(5): 57-63 (doi: 10.1016/S0161-5890(97)00052-7) (PMID: 9293772).

4. Davies AJ, Lee AM, Taylor C, Clear AJ, Goff LK, Iqbal S, et al. A limited role for TP53 mutation in the transformation of follicular lymphoma to diffuse large B-cell lymphoma. Leukemia 2005; 19(8): 65-70 (PMID: 15902285) (doi: 10.1038/sj.leu.2403802).

5. Gryshchenko I, Hofbauer S, Stoecher M, Daniel PT, Steurer M, Gaiger A, Eigenberger K, Greil R, Tinhofer I. MDM2 SNP309 is associated with poor outcome in B-cell chronic lymphocytic. J Clin Oncol 2008; 26(14): 252-259 (PMID: 18467716) (doi: 10.1200/JCO.2007.11.5212).

6. Apte SS, Mattei MG, Olsen BR. Mapping of the human BAX gene to chromosome 19q13.3 - q13.4 and isolation of a novel alternatively spliced transcript, BAX delta. Genomics 1995; 26(3): 592-594 (PMID: 7607685).

7. Faloon P, Arentson E, Kazarov A, Deng CX, Porcher C, Orkin S, Choi K. Basic fibroblast growth factor positively regulates hematopoietic development. Development 2000; 127(9): 1931-1941 (PMID: 10751181).

8. Mathew CC. The isolation of high molecular weight eucariotic DNA // Methods in Molecular Biology / ed. J. M. Walker. N. Y.; L.: Human Press, 1984, Vol. 2: 31-32.

9. Mycko $M$, Kowalski W, Kwinkowski $M$, Buenafe $A C$, Szymanska $B$, Tronczynska E, Plucienniczak A, Selmaj K. Multiple sclerosis: the frequency of allelic forms of tumor necrosis factor and lymphotoxinalpha. J Neuroimmunol 1998; 84: 198-206 (PMID: 9628463).

10. Alavi A, Hood JD, Frausto R. Role of Raf in vascular protection from distinct apoptotic stimuli. Science 2003; 301: 94-100 (doi: 10.1126/science.1082015).

Authors:

Bulat A. Bakirov - MD, PhD, Professor Assistant, Department of Hospital Therapy, Bashkir State Medical University, Ufa, Russia;

D.O. Karimov - MD, Assistant, Department of Biology, Bashkir State Medical University, Ufa, Russia;

T.V. Viktorova - MD, D.Sc., Professor, Head of Department of Biology, Bashkir State Medical University, Ufa, Russia. 